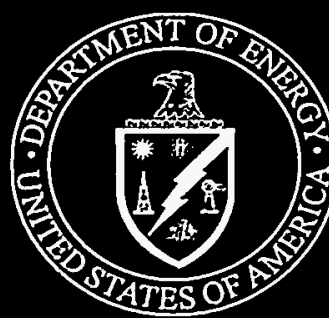

United States

DOE/DP-0132

Department of Energy

November 1995

\title{
Manufacturing Research \\ Strategic Plan
}

Office of Defense Programs

1000 Independence Avenue, S.W. 


\section{DISCLAIMER}

This report was prepared as an account of work sponsored by an agency of the United States Government. Neither the United States Govemment nor any agency thereof, nor any of their employees, makes any warranty, express or implied, or assumes any legal liability or responsibility for the accuracy, completeness, or usefulness of any information, apparans, product, or process disclosed, or represents that its use would not infringe privately owned rights. Reference herein to any specific commercial product, process, or service by trade name, trademark, manufacturer, or otherwise does not necessarily constitute or imply its endorsement, recommendation, or favoring by the United States Government or any agency thereof. The views and opinions of authors expressed herein do not necessarily state or reflect those of the United States Government or any agency thereof.

This report has been reproduced directly from the best available copy.

Available to DOE and DOE Contractors from the Office of Scientific and Techuical Information, P.O. Box 62, Oak Ridge, TN 37831: prices available from (615) $576-8401$.

Available to the public from the U.S. Department of Commerce, Technology Administration. National Technical Information Service, Springfield, VA 22161. (703) $487-4650$ 
August 20, 1995

Dr. Bharat Agrawal

U.S. Department of Energy

Office of Defense Programs, DP-11

19901 Germantown Rd.

Germantown, MD 20874

Dear Dr. Agrawal:

We are pleased to submit the enclosed Draft Manufacturing Strategic Plan for DOE/DP. As you know, this Draft Plan is the result of a collaborative planning effort conducted by a team comprised of members from Lawrence Livermore National Laboratory, Los Alamos National Laboratory, Sandia National Laboratories, and DOE/DP-11. We think that it represents an important step in focusing the Advanced Manufacturing Program within the Weapons RD\&T effort. We believe that this Plan will provide an important structure to help DOE more effectively provide technical solutions in Advanced Manufacturing in order to meet critical Weapons Programmatic needs.

This Draft has been reviewed by management within the Laboratories, and their comments have been incorporated into the enclosed Draft Plan. We recommend that the Plan be published by you and then implemented at the laboratories.

Sincerely yours,

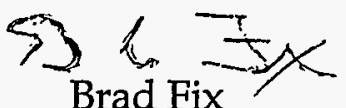

Lawrence Livermore National Laboratory<smiles>C1CC2CCC12</smiles>

Duane Lindner Sandia National Laboratories

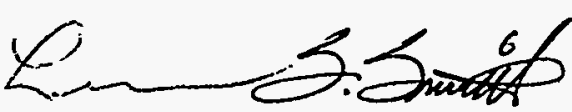

Stan Smith

Lawrence Livermore National Laboratory

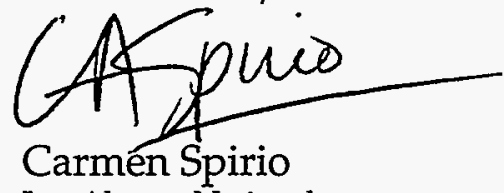

Carmen Spirio

Los Alamos National Laboratory

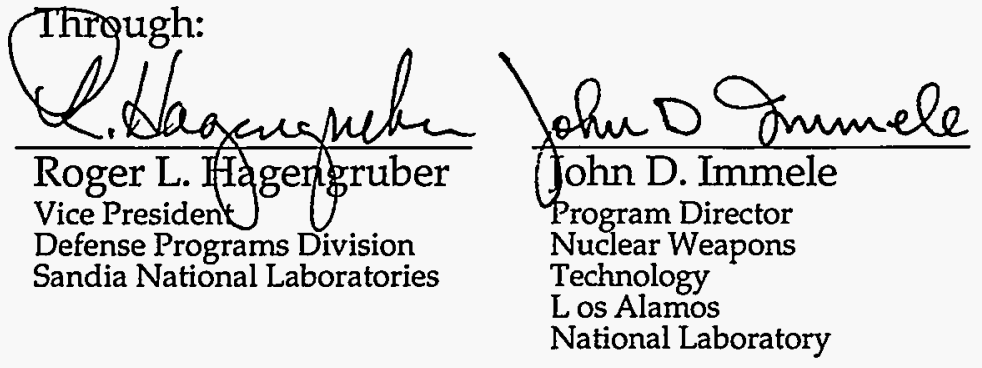

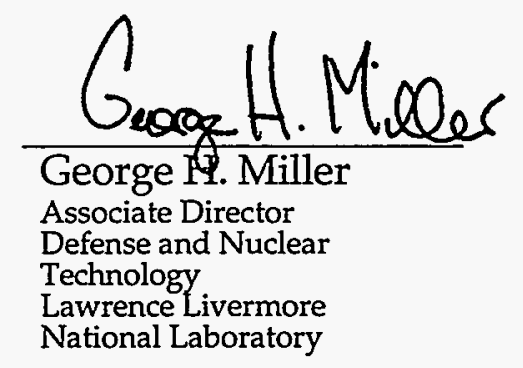




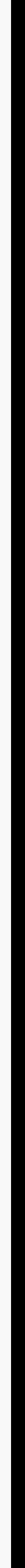




\section{Manufacturing Research}

\section{Strategic Plan}

Office of Defense Programs

1000 Independence Avenue, S.W.

Washington, D.C. 20585 
$\therefore$, sin 


\section{Department of Energy \\ Office of Defense Programs \\ Manufacturing Research \\ Strategic Plan}

\section{Executive Summary}

This plan provides an overall strategic roadmap for the DOE-Defense Programs Advanced Manufacturing Research Program which supports the national ScienceBased Stockpile Stewardship Program. This Plan presents a vision required to support SBSS in developing the knowledge base needed to ensure an enduring national capability to rapidly and effectively manufacture nuclear weapons. This Plan establishes goals to realize the vision and presents the strategies needed to meet those goals within five Advanced Manufacturing Focus Areas. These Focus Areas include: capture the manufacturing knowledge base; product design and enterprise concurrency; simulation and modeling; development of tools, methods, and processes for fabrication and assembly; and networking and information infrastructure. By implementing this Plan, the Defense Programs National Laboratories will become a manufacturing science and technology leader for small lot, inherently safe, ultrareliable systems and components. They will accomplish this by leveraging advances in chemistry and materials, engineering sciences, information sciences, and fabrication technology and through interactions with U.S. industry. Background information, other planning processes, and national and international environments are presented to establish the focus and direction of this plan. 


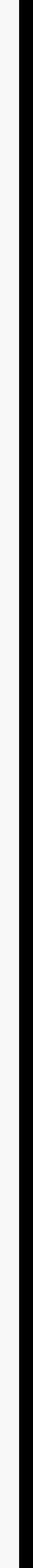




\section{Contents}

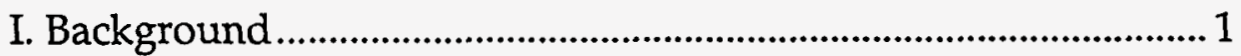

II. The Strategic Planning Process ........................................................ 1

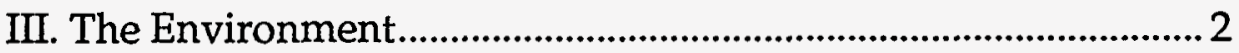

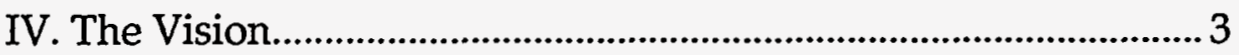

V. Advanced Manufacturing Focus Areas.............................................. 3

(A) Capture the Manufacturing Knowledge Base...................... 3

(B) Product Design and Enterprise Concurrency ….................... 4

(C) Simulation and Modeling ...................................................... 5

(D) Development of Tools, Methods, and Processes for Fabrication and Assembly ...................................................... 6

(E) Networking and Information Infrastructure......................... 7

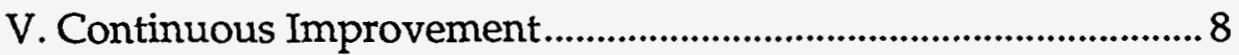

Appendix: Definitions................................................................... 


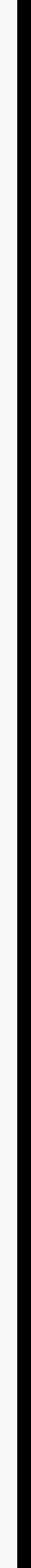




\section{Background}

We are in the midst of a dramatic reorientation of the way the nation thinks about role of nuclear weapons and deterrence. This reorientation is, of course, driven by the fact that the Cold War has ended and the monolithic nuclear threat posed by the Soviet Union has significantly receded. The nation and the DOE are now planning for a future in which nuclear deterrence is based on capability and not capacity. The goal is to rely on a much smaller stockpile along with the ability to rapidly produce limited numbers of remanufactured weapons to meet unforeseen threats.

It is essential to maintain and support a strong Program in manufacturing research for nuclear weapons because the stockpile, the environment, and the state of technology remain dynamic. For example, as the stockpile ages, we can expect degradation and failure to occur; furthermore, changing perceptions, expectations, and requirements will make it necessary to make stockpile changes for improved quality and surety. In general, we will not be able to simply replicate the manufacturing processes that were used to originally produce systems now in the stockpile- those processes are increasingly unavailable or unusable for a wide range of reasons: facility closure, regulatory changes, complete technical obsolescence, cost, and others.

We must rely on manufacturing research, development, and testing efforts to develop the manufacturing technologies and processes that the DOE will use in the future to ensure that the weapons in the stockpile remain safe and reliable, and to ensure that the U.S. retains the ability to produce weapons in the future.

\section{The Strategic Planning Process}

The Department of Energy has embarked on a Strategic Planning Process designed to identify the issues that must drive the future and to develop strategies that can be implemented to most effectively address those issues. This process will result in a hierarchy of Strategic Plans (and subsequent Implementation Plans) that will provide a comprehensive roadmap to most effectively respond to changing national needs and priorities.

The DOE Strategic Plan "Fueling a Competitive Economy," (dated April, 1994) is the highest level planning document within this hierarchy. Among other things, it identified development of a Stockpile Stewardship Program in fulfilling the national security responsibilities of the Department.

The National Security Strategic Plan (dated April, 1994) specified that the goal of the Stockpile Stewardship Program is to "[m]aintain nuclear weapons technology and competence that are responsive to national security needs-within expected fiscal constraints." To meet this goal, a key strategy is to "[d]evelop and improve programs to retain and enhance the essential level of weapons 
technological and manufacturing competence."

The Stockpile Stewardship Program Strategy (dated October, 1994) has identified a spectrum of programmatic thrusts that must be implemented to support ScienceBased Stockpile Stewardship. One of these programmic thrusts is broadly termed "Manufacturing and Materials Technology."

This Manufacturing Research Strategic Plan is one of two companion plans that are intended to specifically identify the $R \& D$ activities that are required in Chemistry and Materials, and in Advanced Manufacturing to support the Stockpile Stewardship Strategy. These Plans have been developed by a team comprised of members from the DOE-DP and from the three DP laboratories: Los Alamos, Lawrence Livermore, and Sandia National Laboratories. This team has worked both as one body and as two subteams (in the two areas: Chemistry and Materials, Advanced Manufacturing). Draft plans were briefed to a larger collection of knowledgeable individuals within each of the labs. Their comments and suggestions were considered during a rewrite of the plans. The revised documents were then briefed in Headquarters and likewise comments and suggestions from those briefings were incorporated in this revision.

\section{The Environment}

National and international conditions and circumstances impacting nuclear weapons manufacturing research needs are in a period of dramatic reorientation. The collapse of the Soviet threat has led to a continuing reexamination of the role of nuclear weapons in the new global environment. Furthermore, rapidly shrinking budgets have forced the closure or downsizing of many of the production facilities that have been used to produce the weapons now in the stockpile. And changing national defense needs have resulted in the suspension of all phased weapons development activities. In order to maintain a credible deterrent in spite of these dramatic changes, it is essential that the U.S. maintain the competency and capability to sustain the weapons in the stockpile in a safe and reliable condition and to remanufacture and requalify nuclear weapons in limited quantity.

Key aspects of the environment which we must consider are:

- The labs have a mission to develop state-of-the art capabilities in key areas of manufacturing science and technology, including process development.

- Rapid world-wide technological change in manufacturing science and technology are occurring.

- Loss of important laboratory and plant capabilities has occurred and is continuing.

- Restricted capital funding is inhibiting the ability to acquire needed equipment and facilities.

- Mission uncertainties. 
- DP's weapons production system is increasingly susceptible to single-point failures.

- The changing regulatory environment is precluding the use of materials, methods, and processes that have been in use for decades.

- Lack of underground testing, combined with a lack of funding for alternate test methods, prevents assessment of the impact of changing materials and manufacturing methods and processes.

- Uncertainties as to how to do certification or qualification of remanufactured systems.

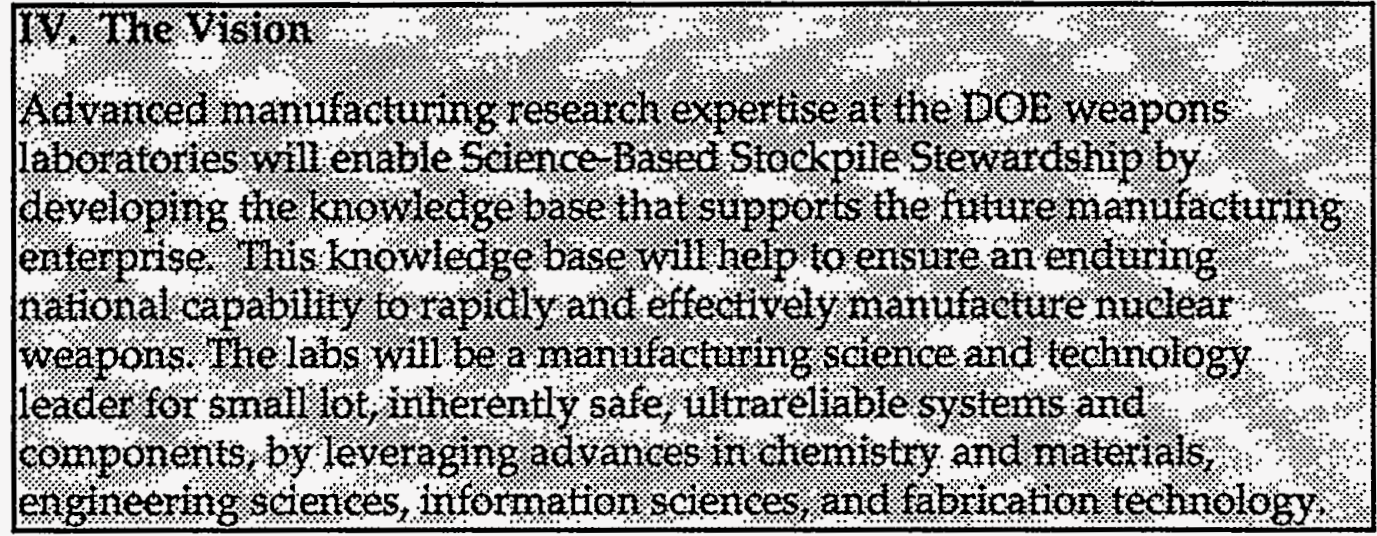

\section{Advanced Manufacturing Focus Areas}

\section{(A) Capture Key Portions of the Manufacturing Knowledge Base.}

Strategic Goal: Understand the baseline manufacturing processes for enduring stockpile systems in order to establish research needs for future systems applications.

Priority Objective: Derive requirements for new or improved manufacturing processes needed for remanufacture of weapons systems or components, and identify engineering test requirements for requalification of systems with remanufactured components.
Key Issues:

- Underground test restrictions and the loss of some environmental test capabilities require new approaches to acceptance testing for remanufactured items and for qualification of remanufactured systems.

- Many manufacturing processes that must be used in the future differ in significant ways from those that have been used historically because of regulatory changes, supplier changes, plant closures, and personnel changes.

- Many processes that have been used in manufacture of weapons, subsystems, and components are incompletely characterized, but were successfully used because of 
confidence based on historical experience.

- Retirements of key personnel within the Nuclear Weapons Complex will further reduce the knowledge base that supports weapons manufacture.

\section{Strategies:}

- Compile archival manufacturing data base from experimental development programs and existing production facilities.

- Characterize and understand key original component fabrication methods and processes.

- Identify alternate materials and manufacturing processes that must be developed and qualified.

- Identify the criteria, processes, and test program needed for qualification of newly manufactured or remanufactured systems.

\section{Success Indicators:}

- Compile roadmap for strategic systems remanufacturing processes, including qualification criteria.

- Data bases are developed and shared.

- Alternate processes have been identified.
(B) Product Design and Enterprise Concurrency

Strategic Goal: Replace serial design and manufacturing engineering with integrated concurrent processes.

Priority Objective: Create a framework for application of new manufacturing tools and methods.

\section{Key Issues:}

- Serial design-to-manufacture processes that have been used in weapons product realization typically result in extended design-to-product cycle times, and increased costs in development and manufacture.

- Future requirements will call for significantly shorter design-toproduction cycles and production quantities will be significantly lower than those of previous programs.

- Tools, methods, and capabilities needed to facilitate concurrent product development and manufacture are not readily available within the DOE nuclear weapons complex.

- Tools that are in use are not generally well integrated across labs, production sites, and private vendors. 
Strategies:

- Establish model-based design as initial step for manufacturing methodology.

- Develop the roadmap for an integrated system of agile manufacturing technologies.

- Create an environment for integrating advanced manufacturing tools and methods, such as concurrent engineering and rapid prototyping.

- Integrate the capabilities and expertise of U.S. industry.

- Establish product design standards for technical information exchange and component fabrication.

\section{Success Indicators:}

- Solid model based rapid manufacturing of weapon systems, including automated capture of design intent.

- Tools that allow optimization of designs for manufacturing are available and in use.

(C) Simulation and Modeling (for Product, Process, and Enterprise)

Strategic Goal: Minimize material use, rework and scrap, and product realization cycle times by optimizing designs and processes for performance and producibility.
Priority Objective: Employ validated simulation and modeling tools which span the spectrum of product, process, and enterprise applications.

\section{Key Issues:}

- Development of weapons systems, subsystems, and components has relied on an expensive and timeconsuming strategy involving an extensive testing cycle.

- Software design tools to simulate product performance and manufacturing processes are not uniformly available or utilized to support weapons design, development, and manufacture.

- Use of existing software tools is complicated because they were written to varying standards, on differing platforms, and without uniform controls.

- Key materials and process information to support simulations is not always readily available.

- Adaptation of new methods to design, develop, and manufacture weapons systems, subsystems, and components must support enhanced surety and improve reliability. 


\section{Strategies:}

- Develop, validate, compile, and share product and process modeling tools and methods.

- Develop and establish model-topart manufacturing processes.

- Develop, validate, and deploy manufacturing enterprise models.

- Develop and incorporate materials properties and characterization data bases for constitutive modeling applications.

- Explore the use of new visualization methods to the enhance utility of simulation and modeling tools.

\section{Success Indicators:}

- A demonstrated capability to fully model and characterize remanufacturing requirements.

- Use of models and tools results in a demonstrable improvements in product or process development cycle time, cost, or product quality.

(D) Development of Tools, Methods, and Processes for Fabrication and Assembly

Strategic Goal: Provide an environment for developing costeffective and flexible manufacturing cells, machines, tooling, and processes for stockpile component, subsystem, and system fabrication.
Primary Objective: Develop, demonstrate, and integrate the tools, cells, and processes needed to reengineer the manufacturing complex.

\section{Key Issues:}

- Manufacturing processes used with nuclear weapons systems, subsystems, and components often rely on expensive, rigid, and inefficient methods and processes.

- Changes in the regulatory environment require the development of new or improved clean manufacturing technologies and processes.

- Lack of agility makes response to changing needs (such as the regulatory environment) expensive and time-consuming.

- Changing skills base requires that fabrication and assembly processes developed and used in the future be robust to personnel and facility changes.

- Downsizing of the existing complex precludes the use of current production lines and processes that have been used for nuclear components.

- Severe limitations on capital equipment are preventing the establishment of needed manufacturing and test capabilities. 
- Agile manufacturing systems require greater investment in planning and design than previous generation manufacturing systems.

\section{Strategies:}

- Develop and validate new technologies, tools, and methods for small lot, reliable product, including rapid prototyping and agile manufacturing processes.

- Develop clean and safe manufacturing processes and technologies.

- Work with suppliers to ensure that developed tools and methods are available for use.

- Develop in-process intelligent closed loop processes for enhanced manufacturing process sensing and control and in-process product acceptance. Support open architecture controllers and algorithms.

- Establish capital equipment procurement and facilities upgrade strategy to support needed manufacturing research capabilities.

\section{Success Indicators:}

- Provide complete manufacturing (fabrication) process characterization to all systems in the enduring stockpile.

- Manufacturing R\&D capabilities are adequately capitalized and maintained.
(E) Networking and Information Infrastructure

Strategic Goal: Provide seamless communications throughout the enterprise and enable connectivity among product realization, manufacturing, , and business processes. Develop the systems and technology to enable the extended enterprise.

Strategic Objective: Enable the integrated architecture (machines, processes, and people) for leveraging manufacturing information for product realization.

Key Issues:

- Communications and information technology will be key to advanced manufacturing systems.

- Full utilization of this potential is limited because of conflicting protocols, strategies, and methods.

- Key communications software tools are missing or not standardized, and available hardware is not widely deployed nor standardized.

- Protection of classified information.

\section{Strategies:}

- Develop and establish transparent information exchange methods and standards for product and process definition, (including industry suppliers). 
- Develop and provide tools and methods for concurrently sharing information and ideas (visualization techniques).

- Develop, plan, and provide for secure, high-speed, reliable networking for stockpile stewardship and stockpile management applications.

\section{Success Indicators:}

- Implemented information exchange and storage processes, using STEP methodology.

- Standards are implemented and in use

\section{Continuous Improvement}

The goals of this plan and the strategies to satisfy those goals are couched in a framework of continuous improvement and focus on national security program requirements. The strategies are presented to help define a roadmap to achieve the expected results in a three to five year time frame, with revisions to this strategic thinking document being provided by changes in national policy, DOE thrust or business areas, and stakeholder input. 


\section{Appendix: Definitions}

Advanced Manufacturing: Use of information in and about manufacturing processes and systems to:

- improve quality

- reduce number of manufacturing processes and steps

- improve process understanding and control

- improve process and system efficiencies

- reduce costs

- reduce cycle time

- reduce product variability

Agile Manufacturing: Small-lot manufacturing environment with sufficient flexibility to allow rapid response to product redesign, or changes in production requirements or scheduling

Components: Functional sub-assembly of the designed weapon.

Fabrication: Materials processing leading to functional components.

Manufacturing: The entire system used to turn raw materials into finished product. Materials processing is a key part of manufacturing.

Production: Fabrication or procurement of components, sub-assemblies, or assemblies suitable for long term deployment in the nuclear weapons stockpile.

Product Realization: The entire process through which concept is converted to actual product.

Qualification: Replacement of weapons system components with remanufactured components does not alter weapon system performance.

Rapid Prototyping: Rapid fabrication of components, subassemblies, or assemblies suitable for demonstrating product performance and production process capabilities at the development level.

Recertification: Validated performance determination.

Remanufacturing: Fabrication of components, sub-assemblies, or assemblies using methods, materials, or resources different from the original quality baseline.

Science-based: The use of the scientific method and a fundamental physics and chemistry based understanding to determine the performance characteristics of components and systems.

STEP: STandard for the Exchange of Product model data. 


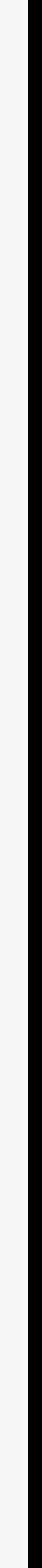



